\title{
Mapeamento geoambiental do município de Casa Branca (SP) como subsídio ao planejamento territorial
}

\author{
Geoenvironmental mapping of the city of \\ Casa Branca (SP), Brazil, as a subsidy to territorial planning
}

\author{
Fábio Augusto Gomes Vieira Reis ${ }^{1}$, Ana Maria Carrascosa do Amaral', \\ Lucilia do Carmo Giordano², Claudia Vanessa dos Santos Corrêa ${ }^{2}$, Camila Jardinetti Chaves ${ }^{2}$ \\ ${ }^{1}$ Departamento de Geologia Aplicada, Instituto de Geociências e Ciências Exatas, Universidade Estadual Paulista "Júlio de \\ Mesquita Filho” - UNESP, Avenida 24-A, 1.515, Bela Vista, CEP 13506-900, Rio Claro, SP, BR (fabioreis@rc.unesp.br) \\ ${ }^{2}$ Programa de Pós-graduação em Geociências e Meio Ambiente, Instituto de Geociências e Ciências Exatas, UNESP, Rio Claro, \\ SP, BR (ana.eng.ambiental@hotmail.com; lilogiordano@gmail.com; claudiageobrax@yahoo.com.br; camila.j.chaves@gmail.com)
}

Recebido em 01 de junho de 2017; aceito em 10 de abril de 2018

\begin{abstract}
Resumo
Os estudos geoambientais, embora recentes, ganham cada vez mais espaço como uma importante ferramenta do planejamento ambiental. O planejador primeiro compartimenta o espaço, buscando entender melhor cada parte que compõe o ambiente, e depois o integra para entender suas interações e otimizá-las. A pesquisa teve como principal objetivo elaborar o mapeamento geoambiental do município de Casa Branca, São Paulo, na escala 1:50.000, considerando critérios fisiográficos, geológico-geotécnicos e de uso e ocupação da terra, incluindo a localização das áreas de preservação permanente (APPs). A técnica utilizada para o zoneamento foi a análise multitemática, na qual são elaborados mapas temáticos, que posteriormente são cruzados, diretamente ou em associações específicas, até se chegar a um mapa final de síntese. As etapas metodológicas do zoneamento incluíram: a compartimentação fisiográfica, o mapeamento do uso e cobertura da terra e da localização das APPs, os trabalhos de campo e, por fim, a integração das informações obtidas. Após a execução de todas as etapas, obteve-se uma carta de unidades geoambientais, a partir da qual foram feitas interpretações sobre as potencialidades e limitações de cada parcela do solo da área de estudo, assim como recomendações, com o intuito de auxiliar no planejamento e nas decisões relacionadas às questões ambientais, além de disponibilizar uma base de dados para futuras pesquisas ambientais na região.
\end{abstract}

Palavras-chave: Análise multitemática; Compartimentação fisiográfica; Unidades geoambientais; Planejamento ambiental.

\begin{abstract}
Even though geoenvironmental studies are recent, they are increasingly gaining importance as an environmental planning tool. At the beginning of the planning process, the planner compartmentalizes the given space, in order to better understand the parts that compose the environment. Then, he or she integrates each part to understand how they interact with each other in order to optimize them. The present project aims to develop geo-environmental zoning in the city of Casa Branca, São Paulo, Brazil at a scale of 1:50.000, considering physiographic, geological/geotechnical, and land use and occupancy criteria, including the location of Permanent Preservation Areas (PPAs). A cross-thematic analysis was the technique used for zoning. A series of thematic maps were drawn up and then subsequently crossed, either directly or in specific associations, until a final summary map was reached. The methodological steps of the zoning processes included: a physiographic subdivision of the area, the mapping of land cover and use, the location of the PPAs, fieldwork, and lastly, the integration of the information obtained. After executing all of the project stages, the map showing the geo-environmental units of the study area was obtained, from which interpretations were made about the potential and the limitations of the area, as well as recommendations. Overall, the aim of the study was to assist in planning and decisions regarding environmental issues in addition to providing a database for future environmental research in the area.
\end{abstract}

Keywords: Cross-thematic analysis; Physiographic subdivision; Geoenvironmental units; Environmental planning. 


\section{INTRODUÇÃO}

O presente trabalho teve como objetivo a elaboração da carta de unidades geoambientais do município de Casa Branca, São Paulo, na escala 1:50.000, considerando critérios fisiográficos, geológico-geotécnicos e de uso e ocupação da terra, incluindo a localização das áreas de preservação permanente (APPs).

O termo geoambiental, adotado pela International Union of Geological Sciences (IUGS), foi criado para denominar a atuação dos profissionais de geociências em meio ambiente, a qual contempla aplicações dos conhecimentos técnicos do meio físico aos diversos mecanismos e instrumentos de gestão ambiental, utilizando a cartografia como ferramenta, que inclui o uso do Sistema de Informação Geográfica (SIG) e de bancos de dados. Segundo Aswathanarayana (1995), o termo "geoambiental" refere-se às porções da litosfera que são afetadas pela ação humana, composta por solos, rochas, fluidos, gases e organismos. Assim, um dos principais objetivos dos estudos geoambientais é o fornecimento de informações integradas sobre as principais características do meio físico e seu comportamento diante das várias formas de uso e ocupação.

O zoneamento geoambiental possibilita a determinação dos potenciais e das limitações de uso dos recursos naturais por meio das condições ecogeodinâmicas da paisagem, possibilitando melhor aproveitamento da área, visando à sua sustentabilidade. As zonas geoambientais são definidas por meio de levantamentos setoriais (como os municípios) e/ou integrados dos recursos naturais e do meio ambiente, cujos dados são trabalhados com a utilização de técnicas de sensoriamento remoto (SR) aéreo, orbital e de geoprocessamento (Moraes, 2007).

As bordas das unidades homogêneas podem ser mapeadas utilizando-se vários critérios para componentes ou atributos agrupados, que apresentam altos graus de correlação (Ferreira e Rossini Penteado, 2011), sendo que a qualidade da unidade delimitada afeta todo o processo de análise e a sua derivação (Lang e Blaschke, 2009). Atualmente, vários métodos para avaliação da estrutura da paisagem estão disponíveis e são baseados, principalmente, em processamento de informação geográfica e dados de SR (Manfré et al., 2015).

Esse tipo de estudo também é empregado direta ou indiretamente como instrumento de gestão ambiental de empreendimentos, como, por exemplo, minerações, hidrelétricas, estradas, túneis, gasodutos, unidades de conservação, aterros sanitários, indústrias, planos diretores municipais, geoturismo, entre outros, assim como na avaliação de impactos sobre o meio físico, na recuperação de áreas degradadas, no monitoramento ambiental, em auditorias ambientais, etc. (Da Silva e Dantas, 2010).

Existem vários procedimentos de espacialização e individualização de unidades do meio físico, como as técnicas de SR e geoprocessamento. A compartimentação fisiográfica pode ser realizada por meio da utilização de processos de fotointerpretação sistemáticos de imagens de satélite, pela análise das várias propriedades da rede de drenagem, a partir da homogeneidade e similaridade das unidades da paisagem (Vedovello, 1993) e pela definição de unidades territoriais básicas (Crepani et al., 1996), pela integração de unidades naturais e antropizadas da paisagem.

Manfré (2015) relatou que muitos autores utilizaram a compartimentação fisiográfica nos estágios preliminares de seus estudos. Dentre eles, podem ser citados Mallick et al. (2014), Kemper e Macdonald (2009), Sharma (2009) e Partridge et al. (2010). Subdivisões fisiográficas são comumente utilizadas como unidades de análise, particularmente em estudos ambientais. Outras abordagens envolvendo utilização de imagens Shuttle Radar Topography Mission (SRTM) ou dados topográficos digitais têm sido propostas por diversos autores, como Drãgut e Eisank (2012) e Camargo et al. (2012).

Em seu trabalho, os autores Chistian e Stewart (1953) descrevem as características geoambientais da área de estudo enfatizando a necessidade da sua compartimentação em unidades geomorfológicas, subdivididas com base nos processos e nas formas do terreno. Essa abordagem baseia-se no princípio de que terrenos que possuem aspectos fisiográficos similares e histórias tectônica e climática parecidas deveriam apresentar comportamento semelhante (Vedovello e Mattos, 1998).

Grecchi (1998) realizou o zoneamento geoambiental na região do município de Piracicaba, São Paulo, com base na análise de atributos do meio físico (geologia, hidrologia, solos, etc.), por meio da compartimentação do terreno em unidades homogêneas, denominadas "landforms". As unidades geoambientais estabelecidas em seu trabalho foram descritas em relação à aptidão agrícola, à erosão, à vulnerabilidade do aquífero e à disposição de rejeitos (Stefani, 2003).

Segundo Pilachevsky (2013), na bibliografia desse tema ainda não existe consenso acerca de como estabelecer os limites das zonas geoambientais. Alguns autores sugerem o uso das unidades geológicas como limites das zonas geoambientais, como é o caso de Rivas et al. (1994). Ohara (1995), assim como Rivas et al. (1994), considera como limite das zonas as rupturas de declividade, que estão geralmente associadas ao limite litológico ou geológico, e com menos frequência aos limites erosivos e de descontinuidade estrutural.

Na pesquisa foram utilizadas as duas abordagens: a análise integrada, para a elaboração da compartimentação da área de estudo, e a análise multitemática, para a elaboração do zoneamento geoambiental.

\section{ÁREA DE ESTUDO}

O município de Casa Branca possui 28.312 habitantes (IBGE, 2010), sendo considerado de pequeno porte. Casa Branca 
sofre com problemas relacionados à falta de planejamento urbano, visto que existem 332 voçorocas na região (Furlani, 1980). Portanto, seria de grande valia a elaboração de estudos relacionados ao meio físico para auxiliar no planejamento ambiental, nas decisões de agentes públicos e privados relacionados as escolhas locacionais e na gestão dos recursos naturais, assegurando à população a conservação dos ecossistemas, a manutenção do capital e a qualidade de vida.

Casa Branca possui $864 \mathrm{~km}^{2}$ e localiza-se no interior do Estado de São Paulo, compreendido entre as coordenadas 265.000 e $300.000 \mathrm{~m}$ E e 7.562 .000 e $7.614 .000 \mathrm{~m} \mathrm{~N}$ (coordenadas UTM), referentes ao meridiano $45^{\circ}$ a oeste de Greenwich (Figura 1).

Aárea de estudo está localizada na borda oriental da Bacia Sedimentar do Paraná, incluindo-se parte do Embasamento Cristalino, no extremo nordeste do município de Casa Branca, representado por rochas cristalinas, como granitos e migmatitos, do complexo Pinhal, do Pré-Cambriano Superior. Sobre esse embasamento foram depositadas unidades da bacia do Paraná, representadas na área pelo Subgrupo Itararé e pela Formação Piraçununga, e coberturas quaternárias. Ocorrem também intrusões de diabásio correspondentes ao magmatismo básico da Formação Serra Geral.

Os sedimentos aluvionares do Quaternário ocorrem ao longo das planícies aluviais, formadas por areias e argilas inconsolidados, com ocorrência de níveis de cascalhos localizados, sendo que essas planícies têm maiores proporções nos Rios Pardo e Jaguari-Mirim. Esses aluviões possuem sedimentos inconsolidados e são formados por areias com granulometria predominante de média a grosseira e argilas orgânicas com alta plasticidade.
Em relação à geomorfologia, a área de estudo compreende três unidades morfoesculturais: a Depressão Periférica (Zona do Mogi Guaçu) que ocupa a maior parte da área; mares de morros do Planalto Cristalino Atlântico que ocupam uma estreita faixa na porção nordeste da área; e cuestas arenito-basálticas, localizadas no extremo oeste (IPT, 1981; Ross e Moroz, 1997; Furlani, 1980). A Depressão Periférica apresenta relevo uniforme de colinas onduladas, morros e morrotes com menores declividades e maiores amplitudes. A maior parte da área de estudo possui altitudes entre 600 e $700 \mathrm{~m}$, sendo a porção sudoeste mais baixa, com altitudes entre 540 a $600 \mathrm{~m}$, e a parte leste com altitudes entre 700 e $800 \mathrm{~m}$.

Amaral et al. (2015) realizaram a compartimentação fisiográfica do município de Casa Branca, São Paulo, levando em conta informações de geologia, geomorfologia, relevo, solos e declividade, definindo, assim, seis unidades fisiográficas, sendo cinco pertencentes à Unidade Morfoescultural do Mogi Guaçu e uma à Unidade Morfoescultural do Planalto Atlântico, descritas no Quadro 1 e na Figura 2.

\section{MATERIAIS E MÉTODOS}

Os materiais utilizados foram:

- cartas vetoriais de mapeamento sistemático do IBGE. Folhas: Casa Branca - Folha SF-23-V-C-V-4 (IBGE, 1972a); Rio Tambaú - Folha SF-23-V-C-V-2 (IBGE, 1972c); São João da Boa Vista - Folha SF-23-V-C-VI-3 (IBGE, 1972b) e São José do Rio Pardo - Folha SF-23V-C-VI-1 (IBGE, 1969);

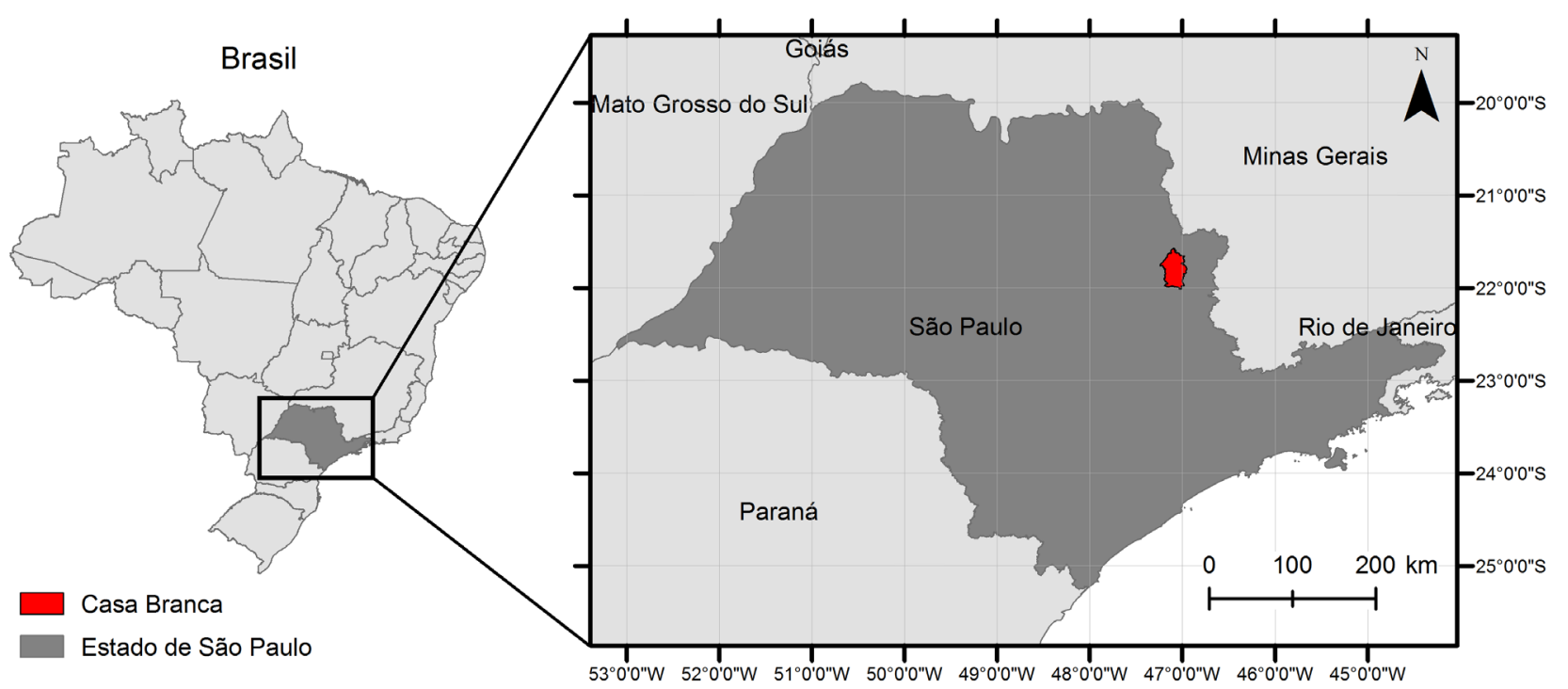

Figura 1. Mapa de localização da área de estudo. 
Quadro 1. Unidades fisiográficas do município de Casa Branca.

\begin{tabular}{|c|c|}
\hline Unidade & Características fisiográficas \\
\hline | - planície aluvionar & $\begin{array}{l}\text { Planícies aluvionares localizadas ao longo dos leitos dos rios, apresentando declividades menores que } \\
3 \% \text { e altitudes variando de } 540 \text { a } 600 \text { m, formadas por areias e argilas inconsolidadas, com ocorrência } \\
\text { de níveis de cascalhos localizados. } \\
\text { São áreas que sofrem periodicamente inundações em épocas de alta pluviosidade, que vão de de- } \\
\text { zembro a fevereiro. Esta unidade também está sujeita à ocorrência de processos erosivos associados } \\
\text { ao solapamento das margens pela erosão hídrica do leito do curso d'água. Desse modo, são áreas } \\
\text { restritas para a expansão urbana. }\end{array}$ \\
\hline $\begin{array}{l}\text { Il - areias e } \\
\text { cascalheiras em } \\
\text { média encosta }\end{array}$ & $\begin{array}{l}\text { Áreas de média encosta da Formação Geológica Pirassununga, bastante suscetíveis à ocorrência de } \\
\text { processos erosivos nas cabeceiras das drenagens, como ocorrência de voçorocas na área de estudo. } \\
\text { As altitudes variam de } 600 \text { a } 800 \mathrm{~m} \text {, e a declividade varia de } 3 \text { a } 12 \% \text {, sendo mais suscetível a proces- } \\
\text { sos erosivos. Em relação às características geológico-geotécnicas, esta unidade possui média a alta } \\
\text { permeabilidade, média a baixa relação de escoamento/infiltração, grande a média espessura do manto } \\
\text { de alteração, topo rochoso profundo, material inconsolidado espesso, média a alta suscetibilidade a } \\
\text { erosão linear, sendo alta para processos erosivos induzidos, e baixa suscetibilidade de ocorrência de } \\
\text { movimentos gravitacionais de massa. Em relação ao uso e à cobertura da terra, esta unidade possui } \\
\text { culturas temporárias e permanentes, além de mata ciliar e área urbana. }\end{array}$ \\
\hline $\begin{array}{l}\text { III - subgrupo } \\
\text { Itararé em média/ } \\
\text { baixa encosta }\end{array}$ & $\begin{array}{l}\text { Médias/baixas encostas do Subgrupo Itararé, que também são suscetíveis à ocorrência de processos } \\
\text { erosivos nas cabeceiras de drenagem, aliados à interferência antrópica, onde há criação de animais } \\
\text { sem o manejo adequado. As altitudes variam de } 540 \text { a } 700 \mathrm{~m} \text {, e a declividade, de } 3 \text { a } 12 \% \text {. O solo è } \\
\text { argiloso-siltoso e apresenta colúvios, representados por grânulos de seixos de quartzos. Quanto às } \\
\text { características geotécnicas, esta unidade possui alta a média permeabilidade, baixa a média relação } \\
\text { escoamento/infiltração, topo rochoso profundo, material inconsolidado espesso, média a alta susceti- } \\
\text { bilidade à erosão linear induzida e baixa suscetibilidade a movimentos gravitacionais de massa. } \\
\text { Quanto ao uso e à cobertura, esta unidade é coberta por cultura temporária e permanente, floresta, } \\
\text { áreas com silvicultura e pastagens. Em campo, não foram verificadas feições erosivas. }\end{array}$ \\
\hline $\begin{array}{l}\text { IV - areias e } \\
\text { cascalheiras em } \\
\text { relevo de morros } \\
\text { com encostas } \\
\text { suavizadas }\end{array}$ & $\begin{array}{l}\text { Esta unidade refere-se aos topos da Formação Pirassununga e Subgrupo Itararé. Esta unidade foi } \\
\text { separada devido ao seu menor potencial erosivo em relação às unidades de encostas. } \\
\text { Suas declividades variam de } 3 \text { a } 12 \% \text {, e as altitudes, de } 540 \text { a } 800 \text { m. Quanto às características } \\
\text { geotécnicas, esta unidade possui alta a média permeabilidade, baixa a média relação escoamento/ } \\
\text { infiltração, grande a média espessura do manto de alteração, material inconsolidado espesso a inter- } \\
\text { mediário, média a alta suscetibilidade à erosão linear induzida e baixa suscetibilidade a movimentos } \\
\text { gravitacionais de massa. Uma característica desta unidade é que as encostas são predominantemente } \\
\text { convexas, sendo ocupadas por culturas temporárias e permanentes, silvicultura, floresta e pastagens. } \\
\text { Embora esta unidade possua média a alta suscetibilidade à erosão linear induzida, em campo, não } \\
\text { foram observadas feições erosivas, possivelmente devido às técnicas de manejo do solo. }\end{array}$ \\
\hline $\begin{array}{l}V \text { - intrusões } \\
\text { básicas em } \\
\text { relevo de morros } \\
\text { com encostas } \\
\text { suavizadas }\end{array}$ & $\begin{array}{l}\text { Intrusões de diabásio, caracterizada pela presença de "terra roxa" e solos de alteração profundos, prin- } \\
\text { cipalmente nos topos, com ocorrência de matacões. As altitudes variam de } 600 \text { a } 800 \text { m, chegando } \\
\text { a valores de } 900 \text { m de altitude no extremo oeste da área de estudo, onde se encontra relevo residual. } \\
\text { Esta unidade possui áreas com média permeabilidade, baixa a média relação escoamento/infiltração, } \\
\text { grande a média espessura do manto de alteração, topo rochoso profundo a intermediário e material } \\
\text { inconsolidado espesso a intermediário. Quanto à suscetibilidade, essas áreas possuem média a baixa } \\
\text { suscetibilidade à ocorrência de erosão linear e de movimentos gravitacionais de massa. São áreas } \\
\text { adequadas à expansão urbana, desde que seja feito um planejamento adequado. Em relação ao uso } \\
\text { e à cobertura da terra, predominam as culturas temporárias, principalmente cana-de-açúcar, seguidas } \\
\text { de culturas permanentes, como laranja, e fragmentos de florestas. }\end{array}$ \\
\hline & $\begin{array}{l}\text { Esta unidade está localizada no extremo nordeste da área de estudo, no complexo migmatítico-graní- } \\
\text { tico. Os vales são abertos, as encostas são predominantemente convexas, com algumas côncavas, a } \\
\text { suscetibilidade à erosão linear induzida é média a alta e a suscetibilidade à erosão linear e movimentos } \\
\text { gravitacionais de massa é baixa. As altitudes variam de } 540 \text { a } 700 \mathrm{~m} \text {. } \\
\text { As áreas inseridas nesta unidade possuem alta permeabilidade, baixa relação escoamento/infiltração, } \\
\text { grande espessura do manto de alteração, topo rochoso profundo e material inconsolidado espesso. } \\
\text { Existem afloramentos de blocos rochosos (matacões), o que denota a potencialidade de rolamento } \\
\text { desses blocos, porém, como a declividade é baixa, de } 0 \text { a } 6 \% \text {, a potencialidade de ocorrência é bai- } \\
\text { xa. O uso predominante é a cultura temporária (cana-de-açúcar) e, em alguns locais, há mata ciliar e } \\
\text { fragmentos de florestas. }\end{array}$ \\
\hline
\end{tabular}




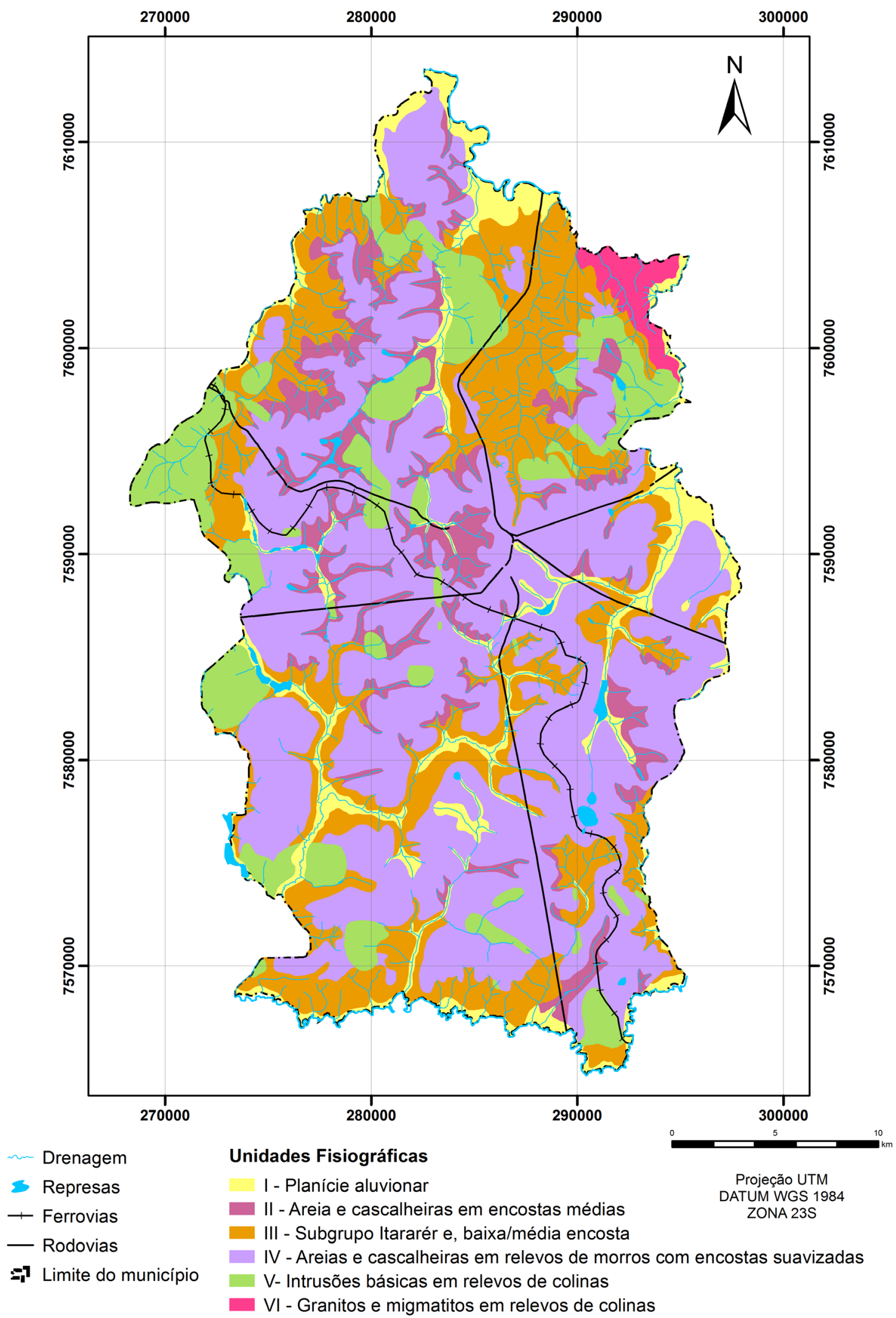

Figura 2. Unidades fisiográficas do município de Casa Branca, São Paulo. 
- produtos de SR: satélite SPOT, com resolução de 2,5 m (ortomosaico recorte na escala 1:25.000, com data de passagem em 2007 e 2010).

Após a coleta do material bibliográfico, cartográfico e de $\mathrm{SR}$, as etapas metodológicas posteriores da pesquisa foram:

1. Elaboração da base cartográfica: os dados vetoriais das cartas do IBGE - drenagens, curvas de nível, represas, principais rodovias, limites municipais e áreas urbanas foram exportados para o formato shapefile, por meio da utilização software ArcGis 10.1 (ESRI, 2011);

2. Tratamento das imagens de $S R$ : fez-se o aumento do contraste linear por meio da manipulação do histograma, remanejando a distribuição dos pixels para aumentar a nitidez da imagem. Na banda 5 , foi feito o processamento de filtragem linear de realce de imagem TM, denominado de filtro Laplaciano. Esse filtro é do tipo passa-alta (Crósta, 1992) e é utilizado para realçar os componentes de alta frequência presentes na imagem, favorecendo as diferenciações e os aspectos texturais (Corrêa, 2013). Segundo Florenzano (2008), esse processamento permite que feições como estradas, drenagens, falhas, juntas e outras feições lineares sejam destacadas na imagem, facilitando, assim, a fotoanálise e a fotointerpretação. Tais procedimentos foram feitos no software SPRING 5.2.3 (Câmara et al., 1996);

3. Compartimentação fisiográfica: para a compartimentação fisiográfica, foi utilizado resultado já obtido pelo trabalho de Amaral et al. (2015), realizado no município de Casa Branca, em que os autores fizeram a compartimentação do município de acordo com o método lógico, referente à análise integrada, conforme Guy (1966), Rivereau (1972), Soares e Fiore (1976) e Zaine (2011). Esse método engloba três etapas principais:

- a fotoleitura, que consiste no reconhecimento e na extração dos elementos de drenagem e relevo da imagem (forma das vertentes, topos de morros e cristas);

- a fotoanálise, que é a associação e a ordenação das partes da imagem analisada (análise da forma, textura e estrutura dos elementos);

- a fotointerpretação, que é a avaliação dos significados e das funções dos objetivos e suas relações por métodos indutivos e dedutivos. Foram utilizadas imagens orbitais de SR em vez de fotografias aéreas, assim, as adaptações propostas por Veneziani e Anjos (1982) foram incorporadas na metodologia. Para as etapas de fotoanálise e fotointerpretação, foi utilizada a metodologia proposta por Zaine (2011).

4. Elaboração do mapa de uso e cobertura da terra e localização das APPs: a localização das APPs foi feita segundo limites do Novo Código Florestal (Brasil, 2012). As APPs nas faixas marginais dos cursos d'água foram mapeadas no ArcGis 10.1 utilizando-se a ferramenta Buffer. Na área de estudo, o Rio Jaguari-Mirim, que limita a área do município na parte sul, possui largura entre 30 e $50 \mathrm{~m}$, portanto, a APP é de $50 \mathrm{~m}$. O mesmo ocorre com o Rio Pardo, que limita o município ao norte. Já o restante dos rios na área de estudo possui largura menor que $10 \mathrm{~m}$, portanto, as APPs são de $30 \mathrm{~m}$. Para as nascentes, foi criado um shapefile do tipo ponto, no qual foram marcadas todas as nascentes para posterior geração da APP de $50 \mathrm{~m}$ pela ferramenta Buffer.

Para a elaboração do mapa de uso e cobertura da terra, foi feita uma classificação por meio da análise visual das imagens do satélite SPOT no software ArcGis 10.1. O uso dessas imagens, com resolução espacial de $2,5 \mathrm{~m}$, possibilitou a interpretação dos alvos em termos de detalhe.

Para a definição das classes de uso e cobertura da terra, foi utilizado como referência o Manual Técnico de Uso da Terra (IBGE, 2006), conforme apresentado no Quadro 2.

Foram definidas 12 classes: área urbana, distrito industrial, cultura temporária, cultura permanente, pastagem, silvicultura, instalações agrícolas, florestas, campo úmido, solo exposto, mineração e reservatórios.

Para a verificação da exatidão do mapeamento de uso e cobertura da terra, foi utilizado o procedimento de estimativa de exatidão da classificação de mapas temáticos proposto por Valeriano (1985). O autor, tomando como base a experiência de Ginevan (1979) e van Genderen e Lock (1977), utiliza uma abordagem fundamentada na estatística para a

Quadro 2. Sistema de classes de uso e ocupação da terra.

\begin{tabular}{|c|c|c|}
\hline Nível I & Nível II & Nível III \\
\hline $\begin{array}{l}\text { Áreas antrópicas } \\
\text { não agrícolas }\end{array}$ & $\begin{array}{c}\text { Área } \\
\text { urbanizada }\end{array}$ & $\begin{array}{c}\text { Área urbana; } \\
\text { distrito industrial; } \\
\text { mineração }\end{array}$ \\
\hline \multirow{6}{*}{$\begin{array}{l}\text { Áreas antrópicas } \\
\text { agrícolas }\end{array}$} & $\begin{array}{c}\text { Cultura } \\
\text { temporária }\end{array}$ & $\begin{array}{c}\text { Cultura } \\
\text { anual (milho, } \\
\text { mandioca, feijão); } \\
\text { cana-de-açúcar }\end{array}$ \\
\hline & $\begin{array}{c}\text { Cultura } \\
\text { permanente }\end{array}$ & Citros; café \\
\hline & Pastagem & $\begin{array}{l}\text { Pasto sujo; } \\
\text { pasto limpo }\end{array}$ \\
\hline & Silvicultura & Eucalipto e pinus \\
\hline & $\begin{array}{l}\text { Instalações } \\
\text { agrícolas }\end{array}$ & \\
\hline & Solo exposto & \\
\hline \multirow{2}{*}{$\begin{array}{l}\text { Áreas de } \\
\text { vegetação natural }\end{array}$} & Florestas & \\
\hline & Campo úmido & \\
\hline Água & $\begin{array}{c}\text { Corpos de água } \\
\text { continentais }\end{array}$ & $\begin{array}{l}\text { Cursos d'água; } \\
\text { reservatório }\end{array}$ \\
\hline
\end{tabular}

Fonte: adaptado de IBGE, 2006. 
análise do mapeamento da cobertura vegetal da terra que é aplicável em qualquer situação contextual.

Segundo esses autores, para verificar a exatidão cartográfica, o primeiro passo é definir o tamanho da amostra, ou seja, a quantidade de pontos a serem verificados nas atividades de campo. Assim, escolhe-se arbitrariamente, a partir da tabela que correlaciona o tamanho amostral com o erro assumido do consumidor receber um mapa abaixo das especificações e do produtor do mapeamento ter de refazer o trabalho, o número de amostras de campo que se quer checar;

1. Atividades de campo: tiveram como objetivo a realização de ajustes dos limites das unidades fisiográficas definidas, análise das feições de relevo, análise do comportamento geotécnico da área, ou seja, a possibilidade de ocorrência de processos geológicos (especialmente erosão, movimentos de massa, inundação, alagamento e assoreamento) e verificação do uso e ocupação da terra, a fim de atualizar e complementar as informações preliminares feitas nas etapas descritas anteriormente;

2. Elaboração da carta de unidades geoambientais: para a elaboração da carta de unidades geoambientais do município de Casa Branca, na escala 1:50.000, foi utilizada a abordagem multitemática, por intermédio do método de sobreposição ponderada. Nesse procedimento, foram definidos pesos no valor de 0,70 para a carta de compartimentação fisiográfica elaborada por Amaral et al. (2015), devido à integração de vários elementos do meio físico em sua confecção, e de 0,30 para o mapa de uso e cobertura da terra.

Somente o mapa de APPs não recebeu peso, pois foi adicionado posteriormente como um layer. Exceto para o mapa de APPs, as informações foram integradas. Foram quantificadas três classes de zoneamento, sendo atribuídos os valores 1,2 e 3 , em uma ordem crescente de suscetibilidade aos processos do meio físico, tais como: erosão, movimentos gravitacionais de massa, inundação e assoreamento.

Na compartimentação fisiográfica, as classes foram atribuídas conforme as análises fotointerpretadas e feitas em campo para cada unidade delimitada.

\section{RESULTADOS E DISCUSSÃO}

\section{Características de uso e cobertura da terra e localização das áreas de preservação permanente}

Analisando o mapa de uso e cobertura da terra elaborado, apresentado na Figura 3, observa-se que $54 \%$ da área é representada por cultura temporária, com predomínio da cana-de-açúcar; seguido de cultura permanente $(20 \%)$, principalmente laranja e café. As áreas de floresta somam $14 \%$ do total da área do município e estão localizadas principalmente ao longo dos cursos d'água.

$\mathrm{Na}$ área também existem locais com plantio de eucalipto, denominadas silvicultura no mapeamento, somando $5 \%$ do total da área de estudo, destacando-se o Horto Areia Branca, próximo ao distrito de Lagoa Branca.

As áreas de pastagens estão localizadas, principalmente, próximas à vegetação nativa ao longo dos leitos dos rios, representando 3\% da área do município. Também existem algumas minerações de argila ao norte da área urbana.

$\mathrm{Na}$ área de estudo foram delimitadas apenas as APPs no entorno dos cursos d'água, conforme medidas estabelecidas pela Lei n ${ }^{0}$ 12.651/2012 (BRASIL, 2012), uma vez que não ocorrem os outros tipos de APP.

Para a verificação da exatidão do mapeamento de uso e cobertura da terra, neste trabalho optou-se por escolher um tamanho amostral de 110 amostras de campo, nas quais podem ser encontrados 10 erros, o que equivale a uma exatidão mínima de mapeamento de 0,85 e 0,90 .

\section{Unidades geoambientais}

A partir do mapa de compartimentos fisiográficos de Amaral et al. (2015), cada unidade recebeu um peso de acordo com critérios que podem ser observados no Quadro 3. A Unidade $V$ é a que tem menor fragilidade, composta por intrusões de diabásio e com baixo potencial à ocorrência de processos do meio físico, correspondendo, assim, ao peso 1. A Unidade $\mathrm{IV}$ recebeu maior peso em relação à Unidade $\mathrm{V}$ (peso 2), devido à potencialidade média a alta para ocorrência de erosão linear. Esses processos erosivos podem ser acelerados ou deflagrados pelo mau uso da terra e por técnicas inadequadas de manejo. A Unidade VI tem baixo potencial para queda e/ou rolamento de blocos rochosos. Esses blocos estão localizados em pontos isolados, principalmente em locais de atividades de extração mineral para construção de brita para construção civil, ou em taludes de rodovias, assumindo, assim, o peso 2. Já nas Unidades II e III registraram-se algumas voçorocas, por isso, receberam peso 3. A Unidade I recebeu peso 3 devido à presença de APPs e à potencialidade para inundação e assoreamento.

Para o mapa de uso e cobertura da terra, os pesos das classes de fragilidade foram definidos de acordo com Ross (1995), conforme apresentado no Quadro 4.

A partir da atribuição de pesos para cada classe foi feita uma reclassificação dos mapas de compartimentação e de uso do solo, dentro das escalas de peso de 1, 2 e 3; a partir de então, para a sobreposição, foi utilizado o peso $70 \%$ para a carta de compartimentação fisiográfica, devido à integração de vários elementos do meio físico em sua elaboração, enquanto para o mapa de uso e cobertura da terra foi utilizado o peso $30 \%$. 


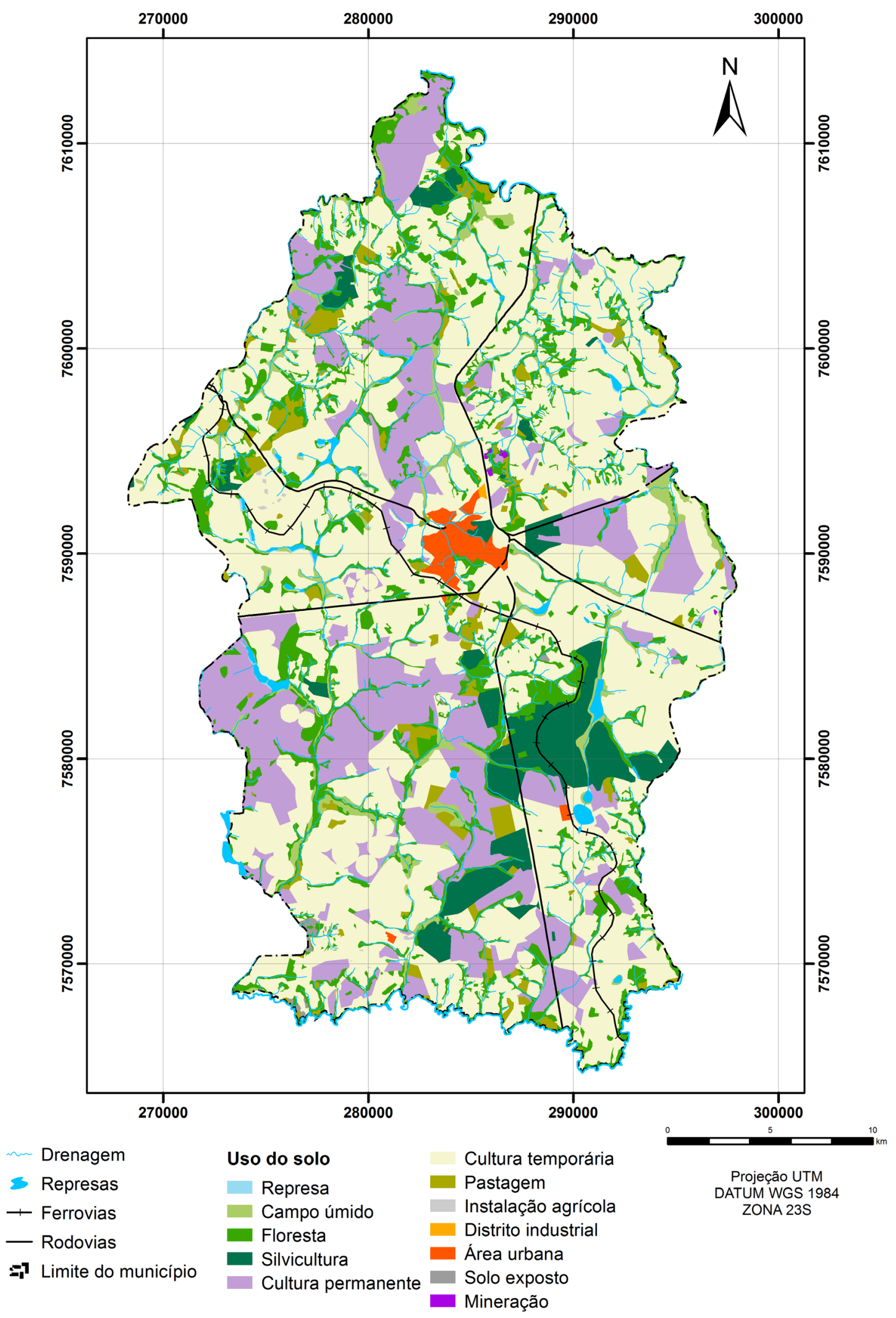

Figura 3. Mapa de uso e cobertura da terra. 
Dessa forma, foram definidas quatro grandes grupos de unidades geoambientais (A, B, C e D), com algumas subdivisões devido ao tipo de uso e cobertura, somando, no total, dez unidades geoambientais, apresentadas na Figura 4 e descritas a seguir. No Quadro 5 estão apresentadas as limitações de cada unidade, assim como as respectivas recomendações e o grau de suscetibilidade à ocorrência de processos do meio físico (movimentos de massa, erosão, inundação e assoreamento).

\section{Unidade geoambiental A}

Esta unidade é caracterizada pela ocorrência de solos argilosos, com denominação "terra roxa", formados a partir da alteração de rochas intrusivas básicas em relevo de morros. A unidade geoambiental A corresponde à Unidade V (intrusões básicas em relevo de morros com encostas suavizadas) e está subdividida em três subunidades, denominadas A1, $\mathrm{A} 2 \mathrm{e} A 3$, devido às suas características de uso e cobertura

Quadro 3. Critérios utilizados para definição dos pesos das unidades fisiográficas.

\begin{tabular}{|c|c|c|}
\hline Peso & Unidades & $\begin{array}{c}\text { Principais critérios } \\
\text { considerados }\end{array}$ \\
\hline 1 (Fraca) & Unidade V & $\begin{array}{l}\text { Baixa potencialidade à } \\
\text { ocorrência de processos do } \\
\text { meio físico } \\
\text { Baixo potencial à queda e/ou ao } \\
\text { rolamento de blocos }\end{array}$ \\
\hline \multirow[t]{2}{*}{2 (Média) } & Unidade IV & $\begin{array}{c}\text { Solos arenosos inconsolidados } \\
\text { com médio/alto potencial à } \\
\text { erosão linear }\end{array}$ \\
\hline & Unidade VI & $\begin{array}{l}\text { Baixo potencial à queda e/ou ao } \\
\text { rolamento de blocos }\end{array}$ \\
\hline \multirow[b]{2}{*}{3 (Forte) } & Unidade I & $\begin{array}{c}\text { Presença de APPs } \\
\text { Áreas sujeitas à inundação e ao } \\
\text { assoreamento }\end{array}$ \\
\hline & $\begin{array}{l}\text { Unidade II/ } \\
\text { Unidade III }\end{array}$ & $\begin{array}{c}\text { Encostas com alto potencial à } \\
\text { erosão linear } \\
\text { Presença de voçorocas } \\
\text { em grande quantidade, } \\
\text { principalmente na Unidade ॥I }\end{array}$ \\
\hline
\end{tabular}

APPs: áreas de preservação permanente.

Quadro 4. Classes de fragilidade do uso e cobertura da terra.

\begin{tabular}{|lc|}
\hline Peso & Uso e cobertura da terra \\
\hline 1 (Fraca) & Floresta e silvicultura \\
2 (Média) & $\begin{array}{c}\text { Cultura permanente, área urbana, instalações } \\
\text { agrícolas, campo úmido e reservatórios }\end{array}$ \\
3 (Forte) & $\begin{array}{c}\text { Cultura temporária, pastagem, distrito industrial } \\
\text { e solo exposto }\end{array}$ \\
\hline
\end{tabular}

Fonte: adaptado de Ross (1995). da terra, sendo a primeira recoberta por floresta; a segunda, por áreas urbanas e culturas permanentes permeadas de campos úmidos, instalações agrícolas e represas; já a terceira é representada pelas culturas temporárias e pastagens.

$\mathrm{Na}$ carta de zoneamento geoambiental, essas três subunidades correspondem aos graus de suscetibilidade baixo, médio e alto em relação à ocorrência de processos do meio físico, como inundação, movimentos de massa e erosão.

\section{Subunidade geoambiental A1}

Representa áreas com baixa ou inexistente potencialidade para a ocorrência de processos do meio físico, devido à sua proteção por vegetação arbórea densa, com sua baixa suscetibilidade natural a esses processos. Esta unidade soma um total de $1,53 \%$ da área de estudo.

No entanto, existe forte pressão de atividades agrícolas instaladas ao seu entorno, e a supressão da vegetação deixará essas áreas suscetíveis. Desse modo, a recomendação é a preservação dessas matas, por meio de legislação, podendo ser integradas à reserva legal das propriedades, ou, então, por meio de técnicas preservacionistas, como é o caso de implantação de corredores ecológicos, para aumentar sua conectividade, uma vez que essas matas se encontram em pequenos fragmentos desconectados na paisagem.

\section{Subunidade geoambiental A2}

Representa 2,10\% da área estudada. Quanto aos processos do meio físico, nessas áreas não há potencial de ocorrência de inundações e movimentos de massa. Recomendam-se o manejo adequado e a elaboração de estudos detalhados para a verificação da presença de matacões que podem dificultar determinados usos.

\section{Subunidade geoambiental A3}

Conta com a maior proporção de áreas, com $8,35 \%$ da área de estudo em terras com intensa atividade agrícola, principalmente cana-de-açúcar, compartilhando outras culturas temporárias. Porém, os processos erosivos podem ocorrer em virtude do manejo incorreto em áreas agrícolas, principalmente em culturas temporárias, assim como em pontos isolados, como em estradas não pavimentadas. Nessas áreas, a presença de blocos rochosos aflorantes em alguns locais dificulta o estabelecimento de determinados usos. Como exemplo, em áreas de plantio, a presença desses blocos dificulta a mecanização da colheita, pois as máquinas podem ser estragadas se esbarrarem com um matacão.

Recomendam-se o manejo adequado e a rotação de culturas nas áreas agrícolas desta unidade, assim como a elaboração de estudos detalhados para a verificação da presença de matacões que podem dificultar determinados usos. 


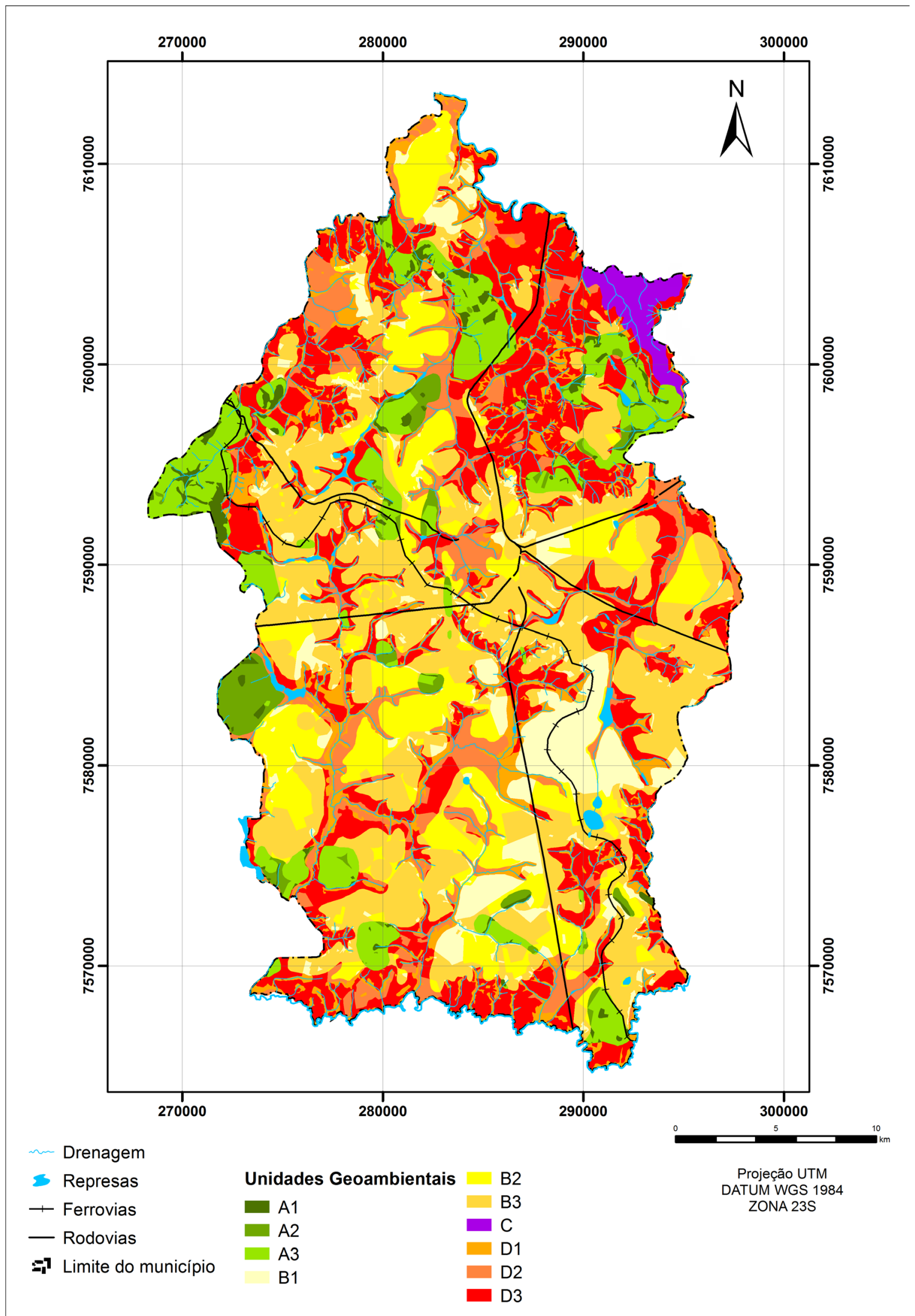

Figura 4. Mapa de unidades geoambientais de Casa Branca, São Paulo. 
Quadro 5. Características das unidades geoambientais.

\begin{tabular}{|c|c|c|c|c|c|}
\hline $\begin{array}{l}\text { Unidade } \\
\text { geoambiental }\end{array}$ & $\begin{array}{l}\text { Unidade } \\
\text { de } \\
\text { Compart. } \\
\text { Fisiog. }\end{array}$ & $\begin{array}{c}\text { Grau de } \\
\text { suscetibilidade } \\
\text { à ocorrência de } \\
\text { processos do } \\
\text { meio físico } \\
\end{array}$ & $\begin{array}{l}\text { Principais } \\
\text { usos do } \\
\text { solo }\end{array}$ & Limitações & Recomendações \\
\hline A1 & 5 & baixo & $\begin{array}{l}\text { Floresta e } \\
\text { silvicultura }\end{array}$ & $\begin{array}{l}\text { São áreas adequadas para } \\
\text { a implantação de corredores } \\
\text { ecológicos e Reservas Legais }\end{array}$ & $\begin{array}{c}\text { Preservação da mata } \\
\text { existente, por meio de } \\
\text { legislação ou técnicas } \\
\text { preservacionistas }\end{array}$ \\
\hline $\mathrm{A} 2$ & 5 & médio & $\begin{array}{l}\text { Área urbana } \\
\text { Campo } \\
\text { úmido } \\
\text { Cultura } \\
\text { permanente } \\
\text { Instalação } \\
\text { agrícola } \\
\text { Represa }\end{array}$ & $\begin{array}{c}\text { São áreas adequadas } \\
\text { para a expansão urbana, } \\
\text { desde que seja feito um } \\
\text { planejamento adequado. } \\
\text { Médias a altas declividades } \\
\text { dificultam a mecanização da } \\
\text { agricultura, assim como a } \\
\text { presença de blocos isolados }\end{array}$ & $\begin{array}{l}\text { Recomenda-se o manejo } \\
\text { adequado e estudos } \\
\text { detalhados para a } \\
\text { verificação de matacões } \\
\text { e blocos rochosos } \\
\text { aflorantes que dificultam } \\
\text { determinados usos }\end{array}$ \\
\hline A3 & 5 & alto & $\begin{array}{c}\text { Cultura } \\
\text { temporária } \\
\text { Pastagem }\end{array}$ & $\begin{array}{l}\text { Médias a altas declividades } \\
\text { dificultam a mecanização da } \\
\text { agricultura, assim como a } \\
\text { presença de blocos isolados }\end{array}$ & $\begin{array}{l}\text { Recomenda-se o manejo } \\
\text { adequado e a rotação } \\
\text { de culturas agrícolas e } \\
\text { estudos detalhados para } \\
\text { a verificação de matacões } \\
\text { e blocos rochosos } \\
\text { aflorantes que dificultam } \\
\text { determinados usos }\end{array}$ \\
\hline B1 & 4 & baixo & $\begin{array}{l}\text { Floresta e } \\
\text { Silvicultura }\end{array}$ & $\begin{array}{c}\text { A supressão da } \\
\text { vegetação aumentará a } \\
\text { suscetibilidade dessas áreas } \\
\text { à erosão linear induzida }\end{array}$ & $\begin{array}{l}\text { Preservação da mata } \\
\text { existente, por meio de } \\
\text { legislação ou técnicas } \\
\text { preservacionistas }\end{array}$ \\
\hline B2 & 4 & médio & $\begin{array}{l}\text { Área urbana } \\
\text { Campo } \\
\text { úmido } \\
\text { Cultura } \\
\text { permanente } \\
\text { Instalação } \\
\text { agrícola } \\
\text { Represa }\end{array}$ & $\begin{array}{c}\text { São áreas adequadas } \\
\text { para a expansão urbana, } \\
\text { desde que seja feito um } \\
\text { planejamento adequado. } \\
\text { O manejo inadequado das } \\
\text { áreas agrícolas pode acelerar } \\
\text { processos erosivos }\end{array}$ & $\begin{array}{l}\text { Práticas conservacionistas } \\
\text { devem ser adotadas para } \\
\text { os processos de erosão } \\
\text { linear; manejo adequado e } \\
\text { a rotação de culturas nas } \\
\text { áreas agrícolas }\end{array}$ \\
\hline B3 & 4 & alto & $\begin{array}{l}\text { Cultura } \\
\text { temporária } \\
\text { Distrito } \\
\text { industrial } \\
\text { Mineração } \\
\text { Pastagem } \\
\text { Solo } \\
\text { exposto }\end{array}$ & $\begin{array}{l}\text { O manejo inadequado das } \\
\text { áreas agrícolas pode acelerar } \\
\text { processos erosivos }\end{array}$ & $\begin{array}{l}\text { Práticas conservacionistas } \\
\text { devem ser adotadas para } \\
\text { os processos de erosão } \\
\text { linear; manejo adequado e } \\
\text { a rotação de culturas nas } \\
\text { áreas agrícolas }\end{array}$ \\
\hline C & 6 & alto & $\begin{array}{c}\text { Cultura } \\
\text { temporária } \\
\text { Distrito } \\
\text { industrial } \\
\text { Mineração } \\
\text { Pastagem } \\
\text { Solo } \\
\text { exposto } \\
\end{array}$ & $\begin{array}{l}\text { Presença de blocos rochosos } \\
\text { localizados que podem } \\
\text { dificultar a instalação de } \\
\text { determinados usos }\end{array}$ & $\begin{array}{c}\text { Preservação da mata } \\
\text { existente e estudos } \\
\text { para verificação da } \\
\text { estabilidade de voçorocas } \\
\text { existentes, assim } \\
\text { como para contenção } \\
\text { de assoreamento e } \\
\text { inundação }\end{array}$ \\
\hline D1 & 1,2 e 3 & baixo & $\begin{array}{l}\text { Floresta e } \\
\text { silvicultura }\end{array}$ & $\begin{array}{c}\text { A supressão } \\
\text { da vegetação aumentará a } \\
\text { suscetibilidade dessas áreas } \\
\text { à erosão linear induzida }\end{array}$ & $\begin{array}{l}\text { Preservação da mata } \\
\text { existente, por meio de } \\
\text { legislação ou técnicas } \\
\text { preservacionistas }\end{array}$ \\
\hline
\end{tabular}


Quadro 5. Continuação.

\begin{tabular}{|c|c|c|c|c|c|}
\hline $\begin{array}{l}\text { Unidade } \\
\text { geoambiental }\end{array}$ & $\begin{array}{l}\text { Unidade } \\
\text { de } \\
\text { Compart. } \\
\text { Fisiog. }\end{array}$ & $\begin{array}{c}\text { Grau de } \\
\text { suscetibilidade } \\
\text { à ocorrência de } \\
\text { processos do } \\
\text { meio físico } \\
\end{array}$ & $\begin{array}{l}\text { Principais } \\
\text { usos do } \\
\text { solo }\end{array}$ & Limitações & Recomendações \\
\hline D2 & 1,2 e 3 & médio & $\begin{array}{l}\text { Área urbana } \\
\text { Campo } \\
\text { úmido } \\
\text { Cultura } \\
\text { permanente } \\
\text { Instalação } \\
\text { agrícola } \\
\text { Represa }\end{array}$ & $\begin{array}{c}\text { A supressão da vegetação } \\
\text { no entorno dos rios pode } \\
\text { aumentar a suscetibilidade } \\
\text { dessas áreas }\end{array}$ & $\begin{array}{c}\text { Preservação da mata } \\
\text { existente e estudos } \\
\text { para verificação da } \\
\text { estabilidade de voçorocas } \\
\text { existentes, assim } \\
\text { como para contenção } \\
\text { de assoreamento e } \\
\text { inundação }\end{array}$ \\
\hline D3 & 1,2 e 3 & alto & $\begin{array}{c}\text { Cultura } \\
\text { temporária } \\
\text { Mineração } \\
\text { Pastagem } \\
\text { Solo } \\
\text { exposto }\end{array}$ & $\begin{array}{l}\text { O manejo inadequado das } \\
\text { atividades agropecuárias pode } \\
\text { acelerar processos erosivos, } \\
\text { a supressão da vegetação } \\
\text { no entorno dos rios pode } \\
\text { aumentar a suscetibilidade } \\
\text { dessas áreas }\end{array}$ & $\begin{array}{l}\text { Recomenda-se estudos } \\
\text { detalhados para a } \\
\text { contenção de processos } \\
\text { erosivos (voçorocas) } \\
\text { e de assoreamento e } \\
\text { inundação, principalmente } \\
\text { próximo à área urbana; } \\
\text { manejo adequado e a } \\
\text { rotação de culturas nas } \\
\text { áreas agrícolas }\end{array}$ \\
\hline
\end{tabular}

\section{Unidade geoambiental B}

Esta unidade corresponde à Unidade IV da Carta de Compartimentação Fisiográfica. Possui baixa, média e alta suscetibilidades à erosão linear induzida, devido ao solo arenoso, e baixa suscetibilidade a movimentos gravitacionais de massa. Foi dividida em três subunidades, B1, B2 e B3 devido às características de uso e ocupação da terra, sendo a primeira coberta por florestas e silvicultura e a segunda por áreas urbanas e culturas permanentes permeadas de campos úmidos, instalações agrícolas e represas; já a terceira é representada pelas culturas temporárias, pastagens, áreas de mineração e solo exposto, além do distrito industrial.

\section{Subunidade geoambiental B1}

Esta subunidade ocupa 7,38\% da área estudada e tem como principal característica a potencialidade baixa ou inexistente para a ocorrência de processos do meio físico. Esta subunidade assemelha-se à subunidade geoambiental $\mathrm{A} 1$, em termos de suscetibilidade à ocorrência de processos do meio físico e recomendações. No entanto, ela foi separada devido às distintas características dos solos provenientes das Formações Pirassununga, Subgrupo Itararé, que são predominantemente arenosos; quando na Unidade A1 são encontrados solos argilosos correlacionados à Formação Serra Geral.

Quanto ao uso e à cobertura, possui florestas e silvicultura, principalmente em áreas de reflorestamento.

\section{Subunidade geoambiental B2}

Esta subunidade, que conta com $12,57 \%$ da área estudada, diferencia-se da subunidade B1 devido ao tipo de uso predominante. O solo é arenoso, com média a alta potencialidade de ocorrência de processos do meio físico, principalmente erosão linear induzida. Contudo, como nas atividades de campo não foram observadas feições erosivas, esta subunidade foi considerada com médio grau de suscetibilidade à ocorrência de processos do meio físico, sendo propícia para a expansão urbana.

Também existem culturas permanentes, como a de laranja e alguns locais com plantações de abacate. O manejo inadequado dessas áreas agrícolas pode acelerar a ocorrência de processos erosivos.

Para essas áreas, recomenda-se a adoção de práticas conservacionistas para os processos de erosão linear, assim como o manejo adequado e a rotação de cultura em áreas agrícolas.

\section{Subunidade geoambiental B3}

Permanecem as mesmas características das subunidades do grupo $\mathrm{B}$, no entanto essa área recobre a maior parte do município de Casa Branca, 25,77\% da área de estudo, sendo o principal uso a cultura temporária, principalmente de cana-de-açúcar, com algumas culturas de milho e soja em pequenas áreas. Para esses usos, as práticas conservacionistas e a rotação de culturas são de grande importância. 


\section{Unidade geoambiental C}

A separação desta unidade se deve ao fato de estar localizada no Embasamento Cristalino, no complexo migmatítico-granítico, referente à Unidade VI da carta de compartimentação fisiográfica.

A principal característica da unidade geoambiental Cé a ampla ocorrência de afloramentos rochosos, representados por matacões. Assim, a ocupação antrópica ou agrícola dessas áreas se torna difícil.

Essas áreas possuem média a alta suscetibilidade à ocorrência de erosão linear induzida. $\mathrm{O}$ grau de suscetibilidade à ocorrência de processos erosivos desta unidade foi considerado médio devido às baixas declividades e amplitudes, tornando baixo o potencial de rolamento ou queda de blocos rochosos.

Recomenda-se a elaboração de estudos detalhados para a verificação da presença de blocos rochosos aflorantes que dificultam a instalação de determinados usos, assim como o manejo adequado das pastagens existentes.

\section{Unidade geoambiental $D$}

Esta unidade geoambiental é a que possui maior grau de suscetibilidade à ocorrência de processos do meio físico. Abrange as Unidades Fisiográficas I, II e III da carta de compartimentação fisiográfica. Está dividida em três subunidades, também devido ao tipo de uso e cobertura da terra. A subunidade D1 é coberta por florestas silviculturas; a subunidade D2, assim como as divisões anteriores, abriga as áreas urbanas e culturas permanentes entremeadas de campos úmidos, instalações agrícolas e represas; já a terceira é representada por culturas temporárias, pastagens, áreas de mineração e solo exposto.

\section{Subunidade geoambiental D1}

Representa 9,85\% da área estudada de planícies aluvionares com solo arenoso, recobertas com florestas e matas ciliares, onde são naturais os processos de inundação e assoreamento no entorno dos cursos d'água.

Nessas áreas existem algumas voçorocas que já estão cobertas por vegetação, denotando um estágio mais avançado da erosão já estabilizada; assim, a supressão da vegetação aumentará sua suscetibilidade à ocorrência de processos erosivos.

São recomendados estudos para a preservação e incrementação das matas ciliares e fragmentos florestais existentes. Essas áreas são impróprias para a ocupação urbana, e, para a instalação agrícola, devendo ser feito um manejo adequado para que não sejam desencadeados processos erosivos. Também se recomenda a realização de estudos para a verificação da estabilidade de voçorocas existentes.

\section{Subunidade geoambiental D2}

Esta subunidade, que conta com $8,91 \%$ da área de estudo, possui alta potencialidade para ocorrência de processos do meio físico, principalmente inundações e assoreamentos nas áreas de planícies aluvionares. Esta subunidade abrange as APPs, sendo, portanto, áreas restritas para a ocupação urbana. No entanto, a área urbana está localizada nessa área, denotando a falta de planejamento urbano no município de Casa Branca.

Também são encontradas áreas com cultura permanente.

Esta subunidade possui a maior parte das voçorocas existentes no município, sendo grande parte delas próxima à área urbana.

Outro problema relacionado a essas áreas é a erosão fluvial, que ocorre em corpos d'água, quando estes estão sem a proteção da mata ciliar e quando não ocorre o manejo adequado.

\section{Subunidade geoambiental D3}

Esta é a porção mais sensível da área de estudo e recobre $22,22 \%$ de seu total, sendo representada pelas porções que, muitas vezes, bordejam as áreas de rios e matas ciliares, representadas por usos como as culturas temporárias, as pastagens, as minerações e os solos expostos.

$\mathrm{O}$ manejo inadequado das atividades agrícolas, assim como a pecuária, e a supressão da vegetação podem ocasionar a ocorrência de processos erosivos. Recomendam-se estudos detalhados para a contenção de processos erosivos, principalmente das áreas nas quais existem voçorocas, e para a contenção de assoreamento e inundação. Também são recomendadas a prática de técnicas conservacionistas de manejo e a rotação de culturas nas áreas agrícolas para promover a proteção do solo.

\section{CONSIDERAÇÕES FINAIS}

A metodologia adotada para a pesquisa, que abarcou tanto a abordagem integrada adotada por Zaine (2011) e Vedovello e Mattos (1998) quanto a abordagem multitemática de Ross (1995), mostrou-se bastante eficiente considerando os resultados obtidos, especialmente em áreas de estudo que não têm mapas temáticos em escalas iguais ao produto do mapeamento geoambiental final. Além do mais, por meio da compartimentação fisiográfica executada na pesquisa, com o auxílio das técnicas de SR e geoprocessamento, obteve-se uma melhor compreensão da área de estudo em termos de especificidades do terreno, mostrando-se um método de fácil e rápida aplicação, com poucos recursos financeiros.

Portanto, espera-se que a presente pesquisa possa dar suporte às decisões do planejamento urbano no município 
de Casa Branca e que os procedimentos descritos possam servir de base para a elaboração de mapeamentos geoambientais em outros municípios.

\section{REFERÊNCIAS}

Amaral, A. M. C., Reis, F. A. G. V., Giordano, L. C., Corrêa, C. V. S., Chaves, C. J. (2015). Compartimentação fisiográfica pela análise integrada: estudo de caso no município de Casa Branca (SP). Geologia USP. Série Científica, 15(1), 15-28. http:/dx.doi.org/10.11606/issn.2316-9095.v15i1p15-28

Aswathanarayana, U. (1995). Geoenvironment: an introduction. Rotterdam: A. A. Balkema.

Brasil. (2012). Lei n ${ }^{\circ} 12.651$, de 25 de maio de 2012. Novo Código Florestal. Brasília.

Câmara, G., Souza, R. C. M., Freitas, U. M., Garrido J. (1996). Spring: Integrating remote sensingand GIS by objectoriented data modelling. Computers \& Graphics, 20(3), 395-403. https://doi.org/10.1016/0097-8493(96)00008-8

Camargo, F. F., Almeida, C. M., Costa, G. A. O. P., Feitosa, R. Q., Oliveira, D. A. B., Heipke, C., Ferreira, R. S. (2012). An open source object-based framework to extract landform classes. Expert Systems with Applications, 39, 541-554. https://doi.org/10.1016/j.eswa.2011.07.044

Christian, C. S., Stewart, G. A. (1953). General Report on Survey of Katherine Darwin Region, 1946. Land Research Series, 1. Austrália: Commonwealth Scientific and Industrial Research Organization.

Corrêa, C. V. S. (2013). Zoneamento geoambiental da região compreendida pelas folhas topográficas São José dos Campos e Jacarei - SP. Dissertação (Mestrado). Rio Claro: Instituto de Geociências e Ciências Exatas, Universidade Estadual Paulista "Júlio de Mesquita Filho" - UNESP.

Crepani, E., Medeiros, J. S., Azevedo, L. G., Duarte, V., Hernandez, P., Florenzano, T. (1996). Curso de sensoriamento remoto aplicado ao zoneamento ecológico-econômico. São José dos Campos: Instituto Nacional de Pesquisas Espaciais - INPE.

Crósta, A. P. (1992). Processamento digital de imagens de sensoriamento remoto. Campinas: Instituto de Geociências, Universidade Estadual de Campinas - UNICAMP.

Da Silva, C. R., Dantas, M. E. (2010). Mapas Geoambientais. Rio de Janeiro. Disponível em: <http://www.cprm.gov.br/
publique/media/mapas_geoambientais_SCGG.pdf $>$. Acesso em: 30 ago. 2012.

Drãgut, L., Eisank, C. (2012). Automated objectbased classification of topography from SRTM data. Geomorphology, 141-142, 21-33. https://doi.org/10.1016/j. geomorph.2011.12.001

ESRI (2011). ArcGIS Desktop: Release 10. Redlands, CA: Environmental Systems Research Institute.

Ferreira, C. J., Rossini Penteado, D. (2011) Mapeamento de risco a escorregamento e inundação por meio da abordagem quantitativa da paisagem em escala regional. In: Congresso Brasileiro de Geologia de Engenharia e Ambiental, 13. São Paulo: ABGE.

Florenzano, T. G. (2008). Geomorfologia: conceitos e tecnologias atuais. São Paulo: Oficina de Textos.

Furlani, G. M. (1980). Estudo geomorfológico das boçorocas de Casa Branca. Dissertação (Mestrado). São Paulo: Faculdade de Filosofia, Letras e Ciências Humanas, Universidade de São Paulo - USP.

Ginevan, M. E. (1979). Testing land-use map accuracy: another look. Photogrammetric Engineering \& Remote Sensing, 45(10), 1371-1377.

Grecchi, R. C. (1998). Zoneamento geoambiental da região de Piracicaba-SP, com auxílio de geoprocessamento. Dissertação (Mestrado). São Carlos: Escola de Engenharia de São Carlos, Universidade de São Paulo - USP.

Guy, M. (1966). Quelques principes e quelques experiences sur la methodologie de la photo-interpretation. In: Simposium Internacional de Photo-Interpretation, 1, 21-41. Paris.

Instituto Brasileiro de Geografia e Estatística - IBGE. (1969). Folha de São José do Rio Pardo. Escala 1:50.000. SF-23V-C-VI-1. São Paulo: IBGE.

Instituto Brasileiro de Geografia e Estatística - IBGE. (1972a). Folha de Casa Branca. Escala 1:50.000. Folha SF-23-V-C-V-4. São Paulo: IBGE.

Instituto Brasileiro de Geografia e Estatística - IBGE. (1972b). Folha de São João da Boa Vista. Escala 1:50.000. SF-23-V-C-VI-3. São Paulo: IBGE.

Instituto Brasileiro de Geografia e Estatística - IBGE. (1972c). Folha do Rio Tambaú. Escala 1:50.000. SF-23-VC-V-2. São Paulo: IBGE. 
Instituto Brasileiro de Geografia e Estatística - IBGE. (2006). Manual Técnico de uso da terra. 2. ed. Rio de Janeiro: IBGE.

Instituto Brasileiro de Geografia e Estatística - IBGE. (2010). Censo demográfico 2010. Disponível em: $<\mathrm{https}$ :// ww2.ibge.gov.br/home/estatistica/populacao/censo2010/ default.shtm>. Acesso em: 10 maio 2013.

Instituto de Pesquisas Tecnológicas do Estado de São Paulo - IPT. (1981). Mapa Geomorfológico do Estado de São Paulo. Escala 1:1.000.000. São Paulo: IPT.

Kemper, J. T., Macdonald, S. E. (2009). Directional change in upland tundra plant communities 20-30 years after seismic exploration in the Canadian low-arctic. Journal of Vegetation Science, 20(3), 557-567. https://doi. org/10.1111/j.1654-1103.2009.01069.x

Lang, S., Blaschke, T. (2009). Análise da paisagem com SIG. São Paulo: Oficina de Textos.

Mallick, J., Al-wadi, H., Rahman, A., Ahmed, M. (2014). Landscape dynamic characteristics using satellite data for a mountainous watershed of Abha, Kingdom of Saudi Arabia. Environmental Earth Sciences, 72(12), 4973-4984.

Manfré, L. A. (2015) Identificação e mapeamento de áreas de deslizamento associadas a rodovias utilizando imagens de sensoriamento remoto. Tese (Doutorado). São Paulo: Escola Politécnica da Universidade de São Paulo - USP.

Manfré, L. A., Nóbrega, R. A. A., Quintanilha, J. A. (2015). Regional and local topography subdivision and landform mapping using SRTM-derived data: a case study in southeastern Brazil. Environmental Earth Sciences, 73(10):6457-6475. https://doi.org/10.1007/s12665-014-3869-2

Moraes, F. T. (2007). Zoneamento geoambiental do planalto de Poços de Caldas, MG/SP a partir de análise fisiográfica e pedoestratigráfica. Tese (Doutorado). Rio Claro: Instituto de Geociências e Ciências Exatas, Universidade Estadual Paulista "Júlio de Mesquita Filho" - UNESP.

Ohara, T. (1995). Zoneamento geoambiental da região do alto-médio Paraíba do Sul (SP) com sensoriamento remoto. Tese (Doutorado). Rio Claro: Instituto de Geociências e Ciências Exatas, Universidade Estadual Paulista "Júlio de Mesquita Filho" - UNESP.

Partridge, T. C., Dollar, E. S. J., Moolman, J., Dollar, L. H. (2010). The geomorphic provinces of South Africa,
Lesotho and Swaziland: A physiographic subdivision for Earth and environmental scientists. Transactions of the Royal Society of South Africa, 65(1), 1-47. https://doi. org/10.1080/00359191003652033

Pilachevsky, T. (2013). Zoneamento geoambiental do município de São João da Boa Vista (SP). Dissertação (Mestrado). Rio Claro: Instituto de Geociências e Ciências Exatas, Universidade Estadual Paulista "Júlio de Mesquita Filho" - UNESP.

Rivas, V., Francés, E., Díaz de Terán, J. R., Cendrero, A., Hidalgo, J., Serrano, A., Villalobos, M., Benito, I., Herrera, M. (1994). Conservation and restoration of Endagered Coastal areas: the case of estuaries in northern Spain. Ocean Costal Management, 23, 129-147. https://doi. org/10.1016/0964-5691(94)90061-2

Rivereau, J. C. (1972). Notas de aulas do curso de fotointerpretação. In: Semana de Estudos - SICEG. Fotografias Aéreas - Aplicações Técnicas. Ouro Preto: SICEG.

Ross, J. L. S. (1995). Análise e síntese na abordagem geográfica da pesquisa para o planejamento ambiental. Revista do Departamento de Geografia, 9, 65-75. http:// dx.doi.org/10.7154/RDG.1995.0009.0006

Ross, J. L. S., Moroz, I. C. (1997). Mapa geomorfológico do Estado de São Paulo. Escala 1:500.000. São Paulo: USP; IPT; FAPESP.

Sharma, A. R. (2009) Community vulnerabilities to climate change and local coping mechanisms in Khudi Watershed. Dissertação (Mestrado). Kritpur, Kathmandu, Nepal: Central Departament of Environmental Sciences, Tribhuvan University.

Soares, P. C., Fiori, A. P. (1976). Lógica e sistemática na análise e interpretação de fotografias aéreas em geologia. Notícias Geomorfológicas, 16(32), 71-104.

Stefani, F. L. (2003). Zoneamento Geoambiental da região de Casa Branca - SP. Dissertação (Mestrado). São José dos Campos: Instituto Nacional de Pesquisas Espaciais - INPE.

Valeriano, D. M. (1985). Processamento digital de dados do MSS-Landsat aplicado ao mapeamento da cobertura da terra da planície costeira do rio Tubarão, SC: metodologia e estimativa de exatidão de classificação. São José dos Campos. Dissertação (Mestrado). São José dos Campos: Instituto Nacional de Pesquisas Espaciais - INPE. 
van Genderen, J. L., Lock, B. F. (1977). Testing land-use map accuracy. Photogrammetric engineering and remote sensing, 43(9), 1135-1137.

Vedovello, R. (1993). Zoneamento geotécnico, por sensoriamento remoto, para estudos de planejamento do meio físico: aplicação em expansão urbana. Dissertação (Mestrado). São José dos Campos: Instituto Nacional de Pesquisas Espaciais - INPE.

Vedovello, R., Mattos, J. T. (1998). A utilização de unidades básicas de compartimentação (UBCs) como base para a definição de unidades geotécnicas: uma abordagem a partir de sensoriamento remoto. In: Simpósio Brasileiro de Cartografia Geotécnica. Florianópolis: ABGE.

Veneziani, P., Anjos, C. E. (1982). Metodologia de interpretação de dados de sensoriamento e aplicações em geologia. São José dos Campos: INPE.

Zaine, J. E. (2011). Método de fotogeologia aplicado a estudos geológico-geotécnicos: ensaio em Poços de Caldas, $M G$. Tese (Livre Docência). Rio Claro: Universidade Estadual Paulista "Júlio de Mesquita Filho" - UNESP. 